\title{
Composição química de silagens de milho cultivado em dois tipos de solos da região norte do Paraná
}

\section{Chemical composition of corn silages produced in two soils of north Paraná}

\author{
Bruno Mazzer de Oliveira Ramos ${ }^{1}$; Andréa Pereira Pinto ${ }^{1}$; Pedro Andrade Katsuki ${ }^{1}$; \\ Geraldo Parra Gomes ${ }^{1}$; Marcos Rodrigues Podleskis ${ }^{1}$; Tomás Folkowskis ${ }^{1}$; \\ Jose Moura Filho $^{1}$; Lincoln Luis Pedrini Soares ${ }^{1}$; Ivone Yurika Mizubuti ${ }^{2 *}$
}

\section{Resumo}

Este trabalho foi realizado com o objetivo de determinar a composição química de silagens de milho produzidas em solos derivados do arenito caiuá e basalto, na região norte do Paraná. Foi utilizado um delineamento experimental inteiramente casualizado com dois tratamentos (solos derivados do arenito caiuá (AC) e basalto (BA) com 18 repetições para solo AC e 13 para solo BA. Determinaram-se os teores de matéria seca, matéria mineral, proteína bruta, fibra bruta, extrato etéreo, fibra em detergente neutro, fibra em detergente ácido, cálcio, fósforo e nutrientes digestíveis totais. A análise de variância não indicou diferença significativa entre os solos arenito caiuá e basalto, do norte do Paraná, para os diferentes componentes analisados nas silagens, provavelmente devido a grande variabilidade observada entre os cultivares. Considerando-se os parâmetros estudados, a Análise de Componentes Principais explicou $65 \%$ da variabilidade entre amostras de silagens de milho de diferentes cultivares provenientes de solos derivados do arenito caiuá e do basalto. EE, NDT, FDA, FDN e FB foram os parâmetros mais importantes para caracterização e diferenciação entre os cultivares, independentemente do tipo de solo. Palavras-chave: Solos, silagem de milho, composição química.

\begin{abstract}
The objective of this study was to determine the chemical composition of corn silages produced in soils originated of arenito caiuá (AC) and basalto (BA) located in North of Paraná. A complete randomized experimental design with two treatments (soils AC and BA), with 18 and 13 replications were used, respectively. The contents of dry matter (DM), mineral matter $(\mathrm{MM})$, crude protein $(\mathrm{CP})$, crude fiber $(\mathrm{CF})$, ether extract (EE), neutral detergent fiber (NDF), acid detergent fiber (ADF), calcium (Ca), phosphorus $(\mathrm{P})$ and total digestible nutrients $(\mathrm{TDN})$ were determined in the samples. The variance analyses did not show significant differences between soils for all components analyzed in the silages. The principal components analysis explained $65 \%$ of the variability between corn silages samples of different cultivars originated of soils AC and BA. The more important parameters for characterization and differentiation between cultivars, regardless of soil's type, were EE, TDN, ADF, NDF and CF.
\end{abstract}

Keywords: Soils, corn silage, chemical composition

\footnotetext{
1 Acadêmicos do Programa de Pós-graduação em Ciência Animal da Universidade Estadual de Londrina (UEL). Londrina, Paraná, Brasil

2 Laboratório de Nutrição Animal. Departamento de Zootecnia. Programa de Pós-graduação em Ciência Animal. Universidade Estadual de Londrina, UEL, C.P. 6001, CEP 86.051-990, Londrina, PR., E-mail: mizubuti@uel.br

* Autor para correspondência.
} 


\section{Introdução}

A distribuição estacional de chuvas no Brasil tem gerado desequilíbrio na produção e na qualidade de forragem, sendo esta abundante no período chuvoso e escasso no período seco (PIMENTEL et al., 1998).

Uma das práticas para melhorar a alimentação do rebanho e minimizar os efeitos da escassez de pastagens no período de estiagem é a conservação de forragens através da ensilagem (ALMEIDA et al., 1995; GUIM; ANDRADE; MALHEIROS, 1995). Para tanto, recomenda-se forrageiras de alta qualidade para os animais e que apresentem elevada produção de massa verde por unidade de área (PIMENTEL et al., 1998). A forrageira comumente recomendada é o milho (Zea mays L.), cujo valor nutritivo é tomado como referência (ALMEIDA et al., 1995; PIMENTEL et al., 1998; PEREIRA et al., 1993).

O cultivo do milho é amplamente disseminado no território nacional e apresenta altos índices de produtividade, com elevados valores energéticos, de matéria seca e de carboidratos solúveis (LAVEZZO; LAVEZZO; SIQUEIRA, 1997). A silagem de milho possui boas características nutricionais, sendo importante na nutrição de vacas leiteiras devido à boa palatabilidade e digestibilidade dos nutrientes, apesar de possuir valores de fibra em detergente neutro entre 45-65\% (MORA et al., 1996).

A conservação do material ensilado é obtida através da fermentação ácida dos açúcares presentes na matéria prima e produção de ácidos lático e acético, com conseqüente redução do $\mathrm{pH}$, inibindo a proliferação de bactérias nocivas ou que deterioram a massa ensilada. Portanto, a qualidade da silagem está relacionada com a proporção dos produtos da fermentação, e depende das partes da planta que compõem o material ensilado. Segundo Harrison et al. (1996) e Nussio e Manzano (1999), a qualidade da silagem de milho está diretamente relacionada à porcentagem de grãos presente na matéria seca do material ensilado e à quantidade de colmos e folhas. À medida que se aumenta a quantidade de grão na matéria seca ensilada, aumenta-se a quantidade de NDT na silagem.
Segundo Roth et al. (1970), os colmos e as folhas são consideradas as partes da planta que possuem menor qualidade nutricional, sendo que existe uma correlação negativa da degradabilidade "in vitro" da fração colmo + folha, com os conteúdos de FDA ($0,99)$, lignina $(-0,81)$ e FDN $(-0,81)$.

No Brasil, o milho é empregado na alimentação humana e como componente básico em rações de animais monogástricos. Segundo informações do IBGE (2000), o Brasil é um dos maiores produtores mundiais de milho, sendo que os estados da região sul e sudeste concentram $70 \%$ do cereal produzido.

A região norte do Paraná é formada por solos de origem basáltica e de origem sedimentar denominado arenito caiuá. Os solos originários do basalto classificam-se predominantemente como terra roxa estruturada (TER) e latossolo roxo e caracterizamse por possuírem textura argilosa e altas concentrações de cátions, tais como: cálcio, magnésio e potássio. Os solos derivados do arenito caiuá, classificam-se em latossolo vermelho escuro (LVE) e podzólico vermelho escuro e caracterizam-se por possuírem textura arenosa e baixas concentrações dos referidos cátions (EMPRESA BRASILEIRA DE PESQUISA AGROPECUÁRIA, 1984).

Em função das características de maior retenção de umidade, os solos de origem basáltica proporcionam maior produtividade da cultura de milho do que aqueles originários do arenito caiuá (GERAGE; SHIOGA, 2000). Entretanto, a qualidade das silagens de milho produzidas nos diferentes solos da região são pouco conhecidas.

Este trabalho teve como objetivo estudar a composição química de silagens de milho produzidas em solos derivados do arenito caiuá e basalto.

\section{Material e Métodos}

As amostras de silagens foram colhidas aleatoriamente de propriedades leiteiras localizadas no norte do Paraná, em regiões de solo derivados do arenito caiuá (AC) e do basalto (BA). Foram co- 
lhidas 31 amostras de silagens de milho de diferentes municípios conforme consta na figura 1 , sendo 18 na região de solo derivado do arenito caiuá e 13 na região de solo basalto. $\mathrm{O}$ delineamento experimental foi o inteiramente casualizado com 2 tratamentos (solo AC e BA) e 18 repetições para o solo $\mathrm{AC}$ e 13 para solo BA.

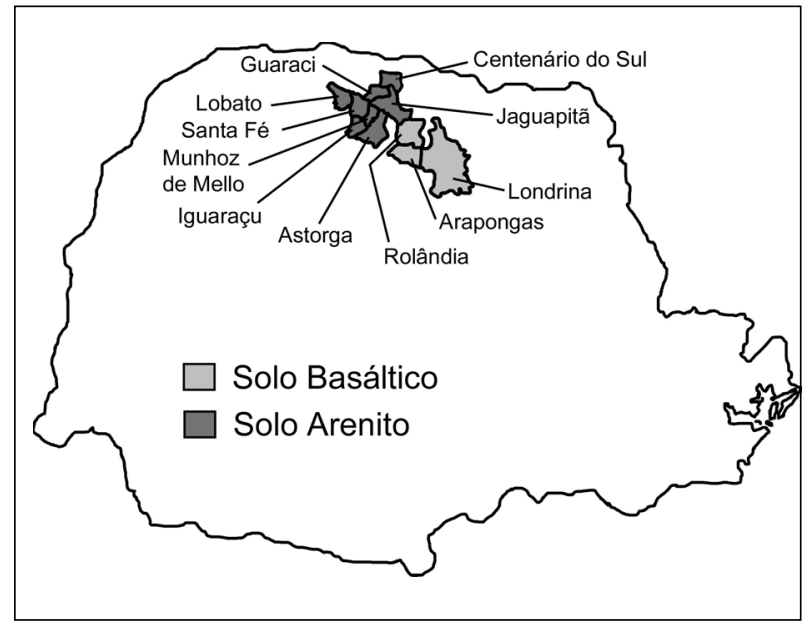

Figura 1 - Locais de coleta de amostra de silagens abrangendo os municípios com regiões de solos derivados do arenito caiuá (AC) e do basalto (BA).

As silagens foram produzidas em meados de dezembro de 2000, janeiro e fevereiro de 2001, e as amostras foram colhidas de silos com mais de 30 dias de fermentação, sendo a maioria em silos de superfície. Apenas uma silagem da região do arenito, em Guaraci, e duas da região de solo basalto, em Rolândia, foram produzidas em silo do tipo trincheira. Foram colhidas amostras representativas de cada silo, obtidas de vários pontos que em seguida foram homogeneizadas, resultando em uma amostra composta de aproximadamente $1 \mathrm{~kg}$. Essas amostras foram encaminhadas no mesmo dia ao Laboratório de Nutrição Animal do Departamento de Zootecnia da Universidade Estadual de Londrina, sendo submetidas à pré-secagem em estufa de circulação de ar forçada à $55^{\circ} \mathrm{C} \pm 5$ por 72 horas. Em seguida, foram moídas em moinho de faca tipo willye, com peneira de crivos de $2 \mathrm{~mm}$.

As determinações de matéria seca (MS), matéria mineral (MM), proteína bruta (PB), fibra bruta (FB) e extrato etéreo (EE) foram realizadas conforme metodologias descritas em AOAC (1990a, b).

Os teores de fibra em detergente ácido (FDA) e fibra em detergente neutro (FDN) foram determinados conforme metodologia desenvolvida por Van Soest (1963) e modificada por Waldern (1971).

O conteúdo de cálcio das amostras foi determinado mediante a precipitação desse elemento na forma de oxalato de cálcio, que foi tratado com ácido sulfúrico para a obtenção de ácido oxálico, e em seguida titulado com permanganato de potássio. $\mathrm{O}$ conteúdo de fósforo foi determinado através do método micro-colorimétrico cujo princípio fundamenta-se na reação do molibdato de amônio com o fósforo formando o complexo fosfomolibdato de amônio, o qual é reduzido pela hidroquinona e sulfito de sódio, conferindo uma coloração azul à solução de molibdeno. A quantidade de fósforo foi determinada medindo-se a intensidade de cor azul em espectrofotômetro (ASSOCIATION OF OFFICIAL ANALYTICAL CHEMISTS, 1990).

O teor de nutrientes digestíveis totais (NDT) foi estimado utilizando-se as fórmulas recomendadas por Mcdowell (1974).

Os dados obtidos foram submetidos à análise de variância utilizando-se o programa Estatística considerando-se como tratamentos os solos AC e BA no qual o milho ensilado foi cultivado.

Para detectar a importância relativa das variáveis na caracterização das amostras, realizou-se ainda análise estatística multivariada utilizando-se o método de Análise de Componentes Principais (ACP) (FLEURY; RIEDWYL, 1988).

\section{Resultados e Discussão}

Os valores médios dos componentes químicos das silagens de milho provenientes de regiões de solo derivados do arenito caiuá e do solo basalto estão apresentados nas tabelas 1 e 2 , respectivamente. 
Tabela 1 - Teores de matéria seca (MS), matéria mineral (MM), proteína bruta (PB), fibra bruta (FB), extrato etéreo (EE), fibra em detergente neutro (FDN), fibra em detergente ácido (FDA), cálcio (Ca), fósforo (P) e nutrientes digestíveis totais (NDT) de silagens de milho cultivados em regiões de solo derivados do arenito caiuá (expressos em base seca).

\begin{tabular}{|c|c|c|c|c|c|c|c|c|c|c|c|}
\hline \multirow{2}{*}{ Amostra } & \multirow{2}{*}{$\begin{array}{l}\text { Cultivar } \\
\text { utilizado }\end{array}$} & \multicolumn{10}{|c|}{ Composição (\%) } \\
\hline & & MS & MM & PB & FB & $\mathrm{EE}$ & FDN & FDA & $\mathrm{Ca}$ & $\mathrm{P}$ & NDT \\
\hline 1 & AG5011 & 23,50 & 7,77 & 5,92 & 29,35 & 3,97 & 74,81 & 39,62 & 0,03 & 0,16 & 60,10 \\
\hline 2 & AG301 & 30,88 & 4,50 & 8,82 & 26,14 & 3,01 & 59,98 & 30,25 & 0,03 & 0,12 & 66,66 \\
\hline 3 & AG301 & 33,93 & 4,46 & 9,75 & 25,11 & 4,78 & 58,98 & 30,05 & 0,03 & 0,23 & 66,80 \\
\hline 4 & AG5011 & 34,91 & 4,75 & 9,60 & 25,97 & 4,14 & 64,36 & 32,98 & 0,03 & 0,26 & 64,75 \\
\hline 5 & MCD & 35,01 & 4,51 & 9,64 & 26,01 & 4,88 & 61,72 & 30,28 & 0,03 & 0,22 & 66,64 \\
\hline 6 & BR201 & 32,68 & 3,57 & 6,15 & 25,67 & 2,76 & 65,82 & 30,37 & 0,03 & 0,25 & 66,58 \\
\hline 7 & MCD & 32,22 & 4,35 & 7,35 & 26,00 & 2,81 & 63,06 & 31,60 & 0,03 & 0,23 & 65,72 \\
\hline 8 & MCD & 37,95 & 6,34 & 6,92 & 26,89 & 2,33 & 65,27 & 31,72 & 0,03 & 0,15 & 65,64 \\
\hline 14 & $\mathrm{MCD}$ & 27,07 & 4,64 & 9,09 & 26,38 & 3,98 & 69,76 & 33,96 & 0,03 & 0,17 & 64,07 \\
\hline 15 & BR601 & 28,47 & 4,77 & 7,79 & 27,75 & 3,63 & 70,91 & 32,61 & 0,03 & 0,19 & 65,01 \\
\hline 16 & MCD & 30,07 & 5,16 & 8,48 & 30,77 & 2,37 & 64,85 & 34,51 & 0,03 & 0,21 & 63,68 \\
\hline 17 & MCD & 30,06 & 4,97 & 8,07 & 30,72 & 2,49 & 69,98 & 33,77 & 0,03 & 0,21 & 64,20 \\
\hline 18 & AG122 & 35,05 & 3,86 & 6,28 & 25,18 & 2,65 & 63,63 & 30,24 & 0,03 & 0,20 & 66,67 \\
\hline 19 & BRASKALB & 22,58 & 6,98 & 7,95 & 31,18 & 1,35 & 70,45 & 37,97 & 0,06 & 0,21 & 61,26 \\
\hline 20 & AG405 & 25,55 & 4,60 & 8,50 & 26,55 & 2,51 & 60,25 & 34,19 & 0,08 & 0,23 & 63,90 \\
\hline 29 & AG405 & 25,14 & 5,74 & 7,22 & 32,01 & 2,17 & 67,07 & 36,69 & 0,04 & 0,13 & 62,15 \\
\hline 32 & AG405 & 27,33 & 5,90 & 6,76 & 35,50 & 2,18 & 76,37 & 44,02 & 0,03 & 0,22 & 57,02 \\
\hline 34 & MCD & 40,22 & 4,63 & 6,01 & 30,96 & 1,40 & 70,51 & 41,46 & 0,03 & 0,13 & 58,82 \\
\hline & Iédias & 30,70 & 5,08 & 7,79 & 28,23 & 2,97 & 66,54 & 34,24 & 0,04 & 0,20 & 63,87 \\
\hline & & $( \pm 4,97)$ & $( \pm 1,08)$ & $( \pm 1,29)$ & $( \pm 2,97)$ & $( \pm 1,04)$ & $\quad( \pm 5,03)$ & $( \pm 4,16)$ & $( \pm 0,01)$ & $( \pm 0,04)$ & $( \pm 2,91)$ \\
\hline
\end{tabular}

$\mathrm{MCD}=$ milho cultivar desconhecido 
Tabela 2 - Teores de matéria seca (MS), matéria mineral (MM), proteína bruta (PB), fibra bruta (FB), extrato etéreo (EE), fibra em detergente neutro (FDN), fibra em detergente ácido (FDA), cálcio (Ca), fósforo $(\mathrm{P})$ e nutrientes digestíveis totais (NDT) de silagens de milho de regiões de solos derivados do basalto (expressos em base seca).

\begin{tabular}{|c|c|c|c|c|c|c|c|c|c|c|c|}
\hline \multirow{2}{*}{ Amostra } & \multirow{2}{*}{$\begin{array}{l}\text { Cultivar } \\
\text { utilizado }\end{array}$} & \multicolumn{10}{|c|}{ Composição (\%) } \\
\hline & & MS & MM & PB & FB & $\mathrm{EE}$ & FDN & FDA & $\mathrm{Ca}$ & $\mathrm{P}$ & NDT \\
\hline 9 & AG5011 & 43,23 & 4,31 & 8,21 & 22,12 & 3,76 & 60,43 & 27,43 & 0,03 & 0,16 & 68,64 \\
\hline 10 & CARGIL 747 & 34,49 & 4,00 & 8,14 & 25,70 & 4,02 & 64,86 & 28,79 & 0,03 & 0,16 & 67,68 \\
\hline 11 & $\mathrm{MCD}$ & 26,47 & 4,67 & 7,66 & 30,45 & 3,93 & 65,93 & 33,58 & 0,03 & 0,24 & 64,33 \\
\hline 12 & AG5011 & 30,30 & 5,85 & 8,12 & 29,59 & 2,29 & 60,60 & 33,33 & 0,03 & 0,20 & 64,51 \\
\hline 13 & MCD & 33,35 & 2,97 & 5,35 & 23,89 & 2,23 & 69,50 & 32,05 & 0,03 & 0,14 & 65,41 \\
\hline 22 & MCD & 23,95 & 5,53 & 8,30 & 29,01 & 2,26 & 66,48 & 35,59 & 0,04 & 0,17 & 62,93 \\
\hline 23 & AG122 & 25,61 & 6,61 & 9,86 & 30,36 & 2,33 & 70,58 & 39,25 & 0,05 & 0,16 & 60,36 \\
\hline 24 & ZN8420 & 32,06 & 5,32 & 8,59 & 28,55 & 3,18 & 57,62 & 37,48 & 0,03 & 0,15 & 61,60 \\
\hline 25 & MCD & 27,66 & 5,90 & 9,31 & 29,60 & 3,21 & 57,97 & 37,73 & 0,04 & 0,23 & 61,43 \\
\hline 26 & AG122 & 32,92 & 4,06 & 8,21 & 27,87 & 3,17 & 66,79 & 35,15 & 0,04 & 0,16 & 63,23 \\
\hline 27 & AG5011 & 31,18 & 4,55 & 8,03 & 24,69 & 3,32 & 53,52 & 30,21 & 0,04 & 0,16 & 66,69 \\
\hline 28 & AG5011 & 25,48 & 5,02 & 10,21 & 26,76 & 2,68 & 56,27 & 31,74 & 0,03 & 0,09 & 65,62 \\
\hline 35 & CARGIL 747 & 36,94 & 4,45 & 8,54 & 25,38 & 2,52 & 72,71 & 31,55 & 0,03 & 0,13 & 65,75 \\
\hline \multicolumn{2}{|c|}{ Médias } & 31,05 & 4,86 & 8,35 & 27,23 & 2,99 & 63,33 & 33,38 & 0,03 & 0,17 & 64,48 \\
\hline \multicolumn{2}{|c|}{ Desvio Padrão } & $( \pm 5,39)$ & $( \pm 0,97)$ & $( \pm 1,17)$ & $( \pm 2,68)$ & $( \pm 0,65)$ & $( \pm 6,01)$ & $( \pm 3,57)$ & $( \pm 0,01)$ & $( \pm 0,04)$ & $( \pm 2,50$ \\
\hline
\end{tabular}

$\mathrm{MCD}=$ milho cultivar desconhecido

A análise de variância não indicou diferença significativa entre tipos de solo para os diferentes componentes analisados nas silagens. Portanto, quando se comparou os teores médios dos componentes químicos da silagem de milho cultivado em ambos os solos (Tabelas 1 e 2) verificou-se que houve pequena ou nenhuma variação dos resultados em função do teor de MS ou do estádio fisiológico da planta ensilada.

As composições químicas das silagens de milho provenientes dos dois tipos de solo (BA e AC) encontradas neste trabalho estão dentro dos limites de variações daqueles encontrados na literatura, os quais foram de 23,22 a 39,60\% de MS; 4,64 a 9,50\% de PB; 1,50 a 4,85\% de EE; 49,10 a 68,00\% de FDN; 23,50 a 43,00\% de FDA e 4,20 a 7,80\% de MM (TOSI et al., 1975; McGUFFEY; SCHINGOETHE, 1980; VALDEZ et al., 1988; PEREIRA et al., 1993; MORA et al., 1996; ALMEIDA et al., 1995; LAVEZZO;
LAVEZZO; SIQUEIRA, 1997; PIMENTEL et al., 1998; ROSTON; ANDRADE, 1992).

Verifica-se que 38,89\% das silagens provenientes de solo originário do arenito caiuá (Tabela 1) e $38,46 \%$ oriundas do solo basalto (Tabela 2), apresentaram teores de matéria seca abaixo de $30 \%$. Entretanto, quando se obteve o teor médio de matéria seca das silagens advindas de cada tipo de solo estudado (AC e BA), cujos valores foram de 30,70 e $31,05 \%$, respectivamente, constatou-se que o milho foi cortado para ensilagem no ponto em que os grãos estavam variando entre a textura pastosa e farináceo-duro, conforme recomendado por Nussio e Manzano (1999), que preconizam o corte do milho quando este apresentar entre 30 a $35 \%$ de matéria seca. Isto demonstra que, em média, $61,32 \%$ das propriedades que confeccionam silagens para alimentação do gado no período de entressafra, o 
fazem de maneira correta, independente da região onde se localizam.

Freitas (1990), relatou que quando as plantas de milho são cortadas para ensilagem com um conteúdo de MS entre 28 a 35\%, estas apresentam um bom acúmulo de nutrientes como um todo. Porém, as plantas em processo de maturidade crescente apresentam um gradual decréscimo no seu teor protéico.

Os teores médios de PB das silagens de milho produzidas em solo AC $(7,79 \pm 1,29)$ foram semelhantes aos observados por Lavezzo, Lavezzo e Siqueira (1997) e Ribeiro et al. (2002), cujos valores foram de 7,52\% e 7,55\%, enquanto que os valores de $\mathrm{PB}$ para as silagens provenientes do solo BA $(8,35 \pm 1,17)$ foram próximos aos valores apresentados por Almeida et al. (1995), Pereira et al. (1993) e Valdez et al. (1988), os quais foram de 8,07\%; $8,02 \%$ e $9,00 \%$, respectivamente.

Os valores médios de FDN e FDA encontrados nas silagens de milho produzidas em solo do tipo AC $(66,54 \pm 5,03$ e $34,24 \pm 4,16$, respectivamente) e BA $(63,56 \pm 6,01$ e $33,44 \pm 3,57$, respectivamente), estão próximos daqueles relatados por Valdez et al. (1988), Almeida et al. (1995) e Lavezzo, Lavezzo e Siqueira (1997). Entretanto, verifica-se que há relatos de diferentes resultados obtidos por outros pesquisadores, tais como, Mora et al. (1996), e Pimentel et al. (1998), que encontraram valores de FDN variando de 51,96 a $60,68 \%$ e valores de FDA variando de 27,90 a $31,94 \%$.

Independente dos solos $\mathrm{AC}$ e $\mathrm{BA}$, o teor de $\mathrm{Ca}$ encontrado nas silagens utilizadas neste trabalho, foi de $0,04 \%$. Este valor está abaixo daqueles apresentados por Valdez et al. (1988), e Pimentel et al. (1998), cujos valores variaram de 0,15 a $4,86 \%$. Por outro lado, o teor de P foi de 0,20 e $0,17 \%$, para solo AC e $\mathrm{BA}$, respectivamente, concordando com os valores apresentados por Pimentel et al. (1998). Porém, esses valores estão abaixo daqueles relatados por Valdez et al. (1988), os quais variaram de 0,55 a $1,44 \%$.

Observa-se que os valores de NDT como indicativo do valor nutritivo das silagens, sofreram pequenas alterações em função da matéria seca do material ensilado. Isto ocorre provavelmente devido à maior quantidade de colmos em relação à matéria seca total da planta, que se observa nos estádios iniciais de maturação e que são gradativamente substituídos pela fração de grãos, responsáveis pela contribuição do teor de energia na MS. Lavezzo, Lavezzo e Siqueira (1997), afirmaram que o teor de NDT como indicativo da eficiência de uso das silagens pelos animais, sofrem pequenas alterações com a evolução da maturação fisiológica, e que com o decorrer da maturação a fração de grãos assumem maior participação na MS da planta.

Embora a análise de variância não tenha indicado diferença significativa entre tipos de solos considerando-se os diferentes componentes químicos analisados nas silagens de milho, observa-se pelas tabelas 1 e 2 que os diferentes cultivares apresentaram variabilidades nas composições. A análise multivariada foi realizada para caracterizar as amostras considerandose a combinação dos parâmetros estudados.

A Análise por Componentes Principais permitiu avaliar quais os parâmetros mais importantes para explicar a variabilidade entre os diferentes cultivares que representaram as amostras de silagens produzidas em regiões de mesmo tipo de solo.

A Figura 2 apresenta a configuração de 18 amostras de silagens de milho produzidas em regiões de solo arenito caiuá (AC) considerando-se os dois primeiros componentes principais (CPs). As amostras estão representadas por seus respectivos cultivares utilizados no trabalho. Verifica-se que os componentes principais (I e II) explicaram, juntos, $64,97 \%$ da variação ocorrida entre as amostras de silagens milho de diferentes cultivares produzidas em solo derivados do arenito caiuá. O primeiro $\mathrm{CP}$ (I) explicou $48,72 \%$ da variabilidade e o segundo (II), foi responsável por $16,25 \%$. Cada componente químico está representado por um vetor e considera-se que, quanto maior o tamanho, maior a importância para explicar a variabilidade entre as amostras. Vetores próximos indicam provável correlação entre si. As análi- 
ses mais importantes para definir o primeiro $\mathrm{CP}$ foram o NDT e o EE positivamente, e a FDN, FDA, FB e MM negativamente.

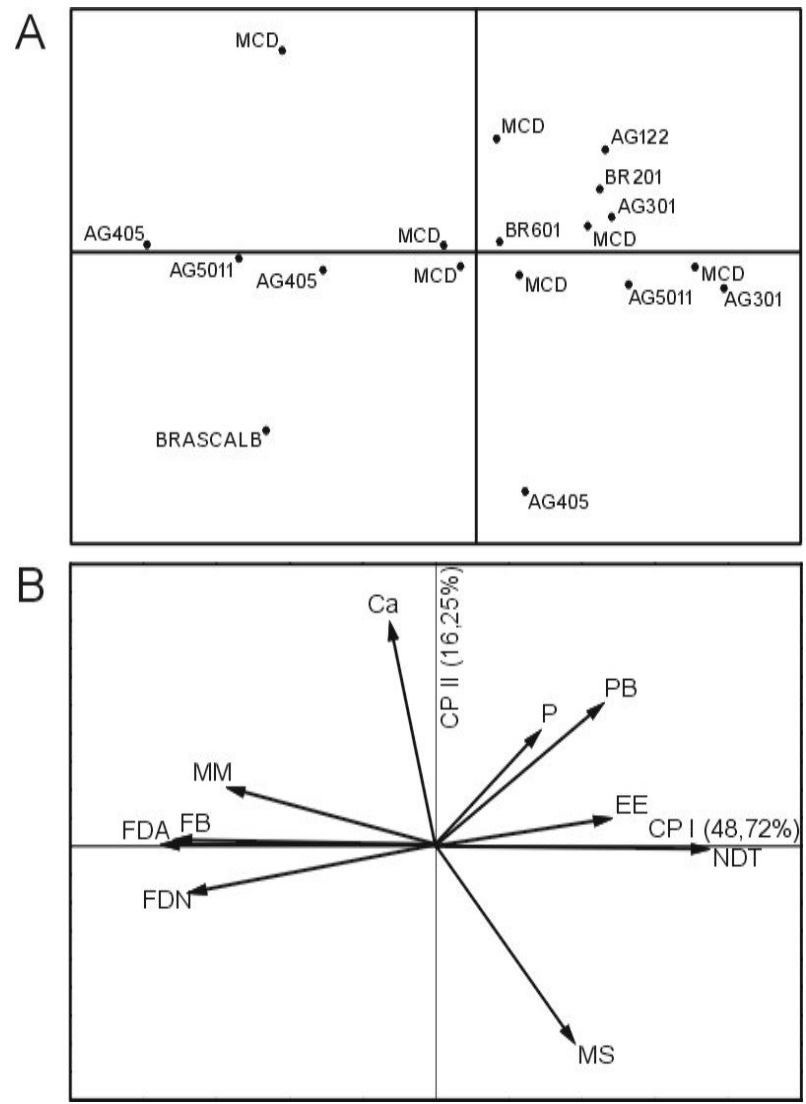

Figura 2 - Projeção dos dados de composição das silagens de milho produzidas em regiões de solos derivado do arenito caiuá, submetidos à análise de componentes principais, considerando-se os cultivares utilizados. (A) configuração das amostras (B) vetores

Os dados de cada amostra são representados de forma gráfica como um ponto no espaço. Amostras com similaridade em uma ou mais propriedades ou relação de propriedades são pontos próximos nesse espaço padrão. As amostras alocadas mais à direita apresentam maiores teores de EE e NDT, e as alocadas mais à esquerda apresentam maiores teores de FDN, FDA, FB e MM. O segundo CP foi definido por MS e Ca inversamente correlacionados.
A Figura 3 apresenta a configuração de 13 amostras de silagens de milho produzidas em regiões de solos derivados do basalto (BA) considerando-se os dois primeiros componentes principais (CPs). O primeiro CP (I) explicou $48,85 \%$ da variabilidade e o segundo (II), foi responsável por 16,07\%. Juntos, os componentes principais I e II, explicaram $64,92 \%$ da variação ocorrida entre as amostras de silagens de milho de diferentes cultivares, obtidas de solos derivados do basalto. As análises mais importantes para definir o primeiro CP foram o FDA, $\mathrm{FB}$ e o $\mathrm{Ca}$ positivamente, e o NDT e a MS negativamente. $\mathrm{O}$ segundo $\mathrm{CP}$ foi definido por EE e FDN inversamente correlacionados.

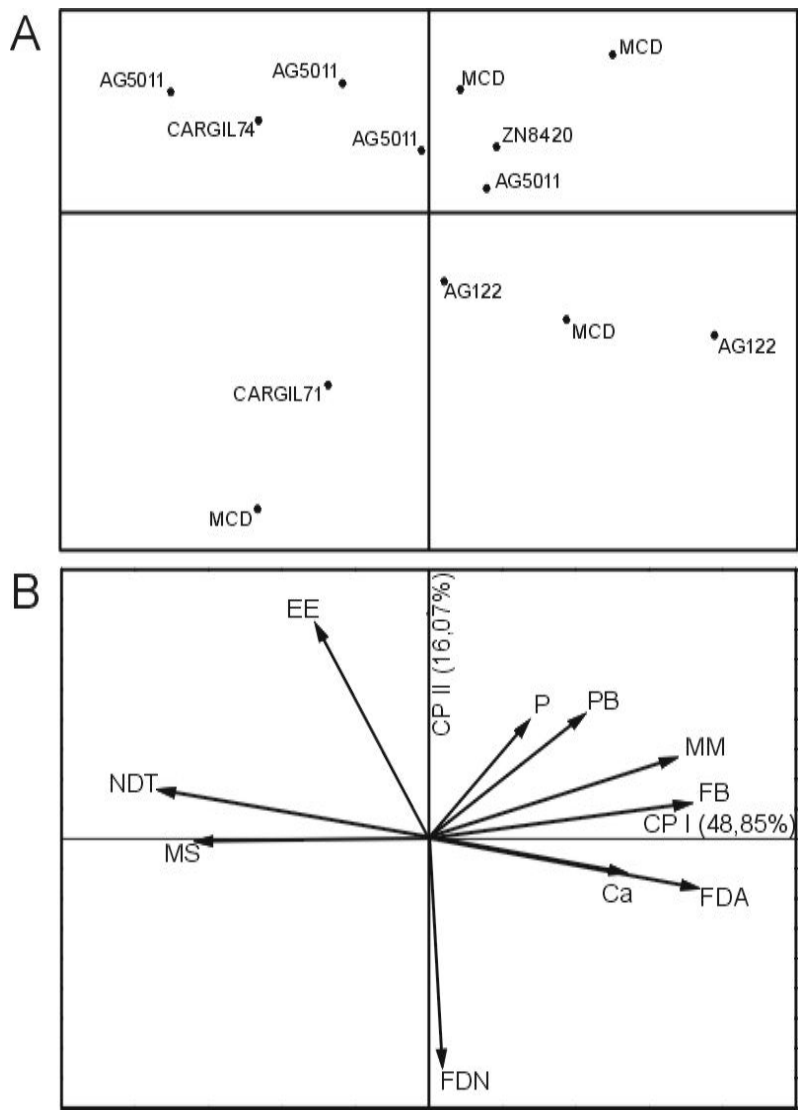

Figura 3 - Projeção dos dados de composição das silagens de milho produzidas em regiões de solos derivados do basalto, submetidos à análise de componentes principais, considerando-se os cultivares utilizados. (A) configuração das amostras (B) vetores. 


\section{Conclusões}

A origem dos solos arenito caiuá e basalto, do norte do Paraná, não influenciaram significativamente os conteúdos de matéria mineral, proteína bruta, fibra bruta, extrato etéreo, fibra em detergente neutro, fibra em detergente ácido, cálcio, fósforo e nutrientes digestíveis totais das silagens de milho.

Considerando-se os parâmetros estudados, a Análise de Componentes Principais explicou $65 \%$ da variabilidade entre amostras de silagens de milho de diferentes cultivares provenientes de solos derivados do arenito caiuá e do basalto, e EE, NDT, FDA, FDN e FB foram os parâmetros mais importantes para caracterização e diferenciação entre os cultivares independentemente do tipo de solo.

\section{Referências}

ALMEIDA, M. F. et al. Composição química e consumo voluntário das silagens de sorgo, em dois estádios de corte, girassol e milho para ruminantes. Ciência e Prática, Lavras, v.19, n.3, p.315-321, 1995.

ASSOCIATION OF OFFICIAL ANALYTICAL CHEMISTS. Official methods of analysis of the Association of Official Analytical Chemists. Arlington: K. Helrich, 1990. 2.v

EMPRESA BRASILEIRA DE PESQUISA AGROPECUÁRIA. Serviço Nacional de Levantamento e Conservação de Solos. Levantamento de reconhecimento dos solos de Estado do Paraná. Curitiba, 1984.

FLEURY, B.; RIEDWYL, H. Multivariate statistics: a practical approach. New York: Chapman and Hall, 1988.

FREITAS, E. A. G. Silagem de milho: Condicionantes do valor nutritivo. Agropecuária Catarinense, Florianópolis, v.3, n.2, p.9-12. 1990.

GERAGE, A. C.; SHIOGA, P. S. Avaliação estadual de cultivares de milho: Safra 1999/2000. Londrina: IAPAR, 2000. (Informe de Pesquisa IAPAR, n.136)

GUIM, A.; ANDRADE, P.; MALHEIROS, E. B. Efeito de inoculante microbiano sobre o consumo, degradação in situ e digestibilidade aparente de silagens de milho (Zea mays L.). Revista da Sociedade Brasileira de Zootecnia, Viçosa, v.24, n.6, p.1045-1053, 1995.
HARRISON, J. H. et al. Effect of harvest maturity of whole plant corn silage on milk production and component yield, and passage of corn grain and starch into feces. Journal of Dairy Science, Savoy, v.79, p.149, 1996. Suppl.

IBGE. Levantamento sistemático da produção agrícola. Rio de Janeiro, 2000.

LAVEZZO, O. E. N. M.; LAVEZZO, W.; SIQUEIRA, E. R. Estádio de desenvolvimento do milho. 2. Efeito sobre o consumo e a digestibilidade da silagem em ovinos. Revista Brasileira de Zootecnia, Viçosa, v.26, n.4, p.683690, 1997.

MCDOWELL, L. R. et al. Tabelas de composição de alimentos da América Latina. Gainesville: Universidade da Flórida, 1974

McGUFFEY, R. K.; SCHINGOETHE, D. J. Feeding value of a high oil variety of sunflowers as silage to lactating dairy cows. Journal of Dairy Science, Savoy, v.63, n.7, p.1109-1113, 1980.

MORA, P. J. G. et al. Digestibilidade aparente dos nutrientes e energia líquida da silagem de milho (Zea mays L.) para vacas lactantes. Revista da Sociedade Brasileira de Zootecnia, Viçosa, v.25, n.2, p.357-368, 1996.

NUSSIO, L. G.; MANZANO, R.P. Silagem de milho. In: SIMPÓSIO INTERNACIONAL SOBRE PRODUÇÃO INTENSIVA DE LEITE, 4., 1999, Caxambu. Anais... Caxambu : [s.n.], 1999. p.44-60.

PEREIRA, O.G. et al. Produtividade de uma variedade de milho (Zea mays $L$.) e de três variedades de sorgo (Sorghum bicolor (L.) Moench) e o valor nutritivo de suas silagens. Revista da Sociedade Brasileira de Zootecnia, Viçosa, v.22, n.1, p.31-38, 1993.

PIMENTEL, J. J. O. et al. Efeito da suplementação protéica no valor nutritivo de silagens de milho e sorgo. Revista Brasileira de Zootecnia, Viçosa, v.27, n.5, p.10421049, 1998.

RIBEIRO, E.L.A. et al. Uso de silagens de girassol (Helianthus annus L.), milho (Zea mays L.) e sorgo (Sorghum bicolor (L.) Moench) para ovelhas em confinamento. Ciência Rural, Santa Maria, v.32, n.2, 2002. (no prelo)

ROSTON, A. J.; ANDRADE, P. Digestibilidade de forrageiras com ruminantes: coletânea de informações. Revista Brasileira de Zootecnia, Viçosa, v.21, n.4, p.647666, 1992

ROTH, L. S. et al. Genetic variation of quality traits in maize (Zea mays, L.) forage. Crop Science, Madison, v.10, p.365, 1970. 
TOSI, H. et al. Avaliação do Girassol (Helianthus annus) como planta para a ensilagem. Revista Brasileira de Zootecnia, Viçosa, v.4, n.1, p.39-48. 1975.

VALDEZ, F. R. et al. In vivo digestibility of corn and sunflower intercropped as a silage crop. Journal of Dairy Science, Savoy, v.71, n.7, p.1860-1867, 1988.
VAN SOEST, P. J. Use of detergents in the analysis of fibrous feeds. II. A rapid method for the determination of fibers and lignin. Journal of the Association of Official Agricultural Chemistis, Washington, v.46, n.5, p.829835, 1963.

WALDERN, D. E. A rapid micro-digestion procedure for neutral and acid detergent fiber. Canadian Journal of Animal Science, Ottawa, v.51, p.67-69, 1971. 
